OPEN ACCESS

Edited by:

Hanlin L. Wang,

University of California, Los Angeles,

United States

Reviewed by:

Jinping Lai,

Kaiser Permanente Sacramento Medical Center, United States

Zongming (Eric) Chen,

Mayo Clinic, United States

*Correspondence:

Tingtao Chen

chentingtao1984@163.com

Zhaoxia Liu

Izxia77@163.com

Specialty section:

This article was submitted to

Cancer Immunity

and Immunotherapy,

a section of the journal

Frontiers in Oncology

Received: 04 January 2022

Accepted: 27 January 2022

Published: 16 February 2022

Citation:

Zhou Y, Liu Z and Chen T (2022) Gut Microbiota:

A Promising Milestone in

Enhancing the Efficacy of

PD1/PD-L1 Blockade Therapy.

Front. Oncol. 12:847350.

doi: 10.3389/fonc.2022.847350

\section{Gut Microbiota: A Promising Milestone in Enhancing the Efficacy of PD1/PD-L1 Blockade Therapy}

\author{
Yuqing Zhou ${ }^{1,2}$, Zhaoxia Liu ${ }^{1 *}$ and Tingtao Chen ${ }^{1,3 *}$ \\ 1 Department of Obstetrics and Gynecology, The Second Affiliated Hospital of Nanchang University, Nanchang, China, \\ ${ }^{2}$ Queen Mary School, Nanchang University, Nanchang, China, ${ }^{3}$ National Engineering Research Center for Bioengineering \\ Drugs and Technologies, Institute of Translational Medicine, Nanchang University, Nanchang, China
}

In the past few decades, immunotherapy has emerged as one of the most promising strategies among current treatments of cancer. In particular, the field of PD1/PD-L1 inhibitors has been boosted, widely applied into clinical practice with potent therapeutic efficacy and remarkable survival benefits on various cancers such as melanoma, nonsmall cell lung cancer (NSCLC), and urothelial carcinoma (UC). However, the application of PD1/PD-L1 blockade therapy is still quite restricted because of unexpected toxicities, limited response rate, as well as associated resistance. In consequence, searching for potential strategies that possibly resolve the existing limitations and enhance the therapeutic responsiveness of PD1/PD-L1 blockade is of great significance. Fortunately, the gut microbiome has been demonstrated to serve as a pivotal regulator in anti-PD1/PD-L1 therapy, providing an applicable tool to improve anti-PD1/PD-L1 clinical efficacy. In this review, we summarized published advancements about how microbiota modulated in anti-PD1/PD-L1 therapy and illustrated its underlying mechanisms, giving insights into putative manipulation of gut microbiota to facilitate PD1/PD-L1 blockade.

Keywords: cancer, immunotherapy, PD1/PD-L1, gut microbiome, probiotics

\section{INTRODUCTION}

Cancer is a multistep disorder that arises through a combination of genetic and epigenetic alterations, which ultimately facilitate malignant transformation and cell immortality (1). According to the estimation of Disability-Adjusted Life Years (DALYs), malignancies possess the most considerable global burden amongst all human diseases, which are estimated to become the leading cause of mortality by the end of $2060(1,2)$. To date, surgery, chemotherapy, and radiotherapy remain the mainstream for standard cancer strategies; however, risks for posttherapeutic side effects, including accidental infection, immunity suppression, and multi-drug resistance (MDR) still exist when applying these current methods (3-5). Therefore, concerning the undesirable reactions of conventional cures, the focus has been shifted to more precisely targeted cancer immunotherapies, with the hope to elude the above by-effects, emerging as one of the standard anti-tumor therapies in clinical fields $(6,7)$. 
In terms of immunotherapies, immune checkpoint inhibitors (ICIs) are regarded as one of the most crucial counterparts in treating a number of advanced cancers, especially for the application of programmed cell death 1 (PD1) and programmed cell death 1 ligand 1 (PD-L1) inhibitors $(3,6,8)$. The monoclonal antibodies against PD1 and PD-L1 specifically target and block these two immunoregulatory sites, largely unleashing the immunotolerance and strengthening the antitumor immunity via impeding the inhibitory signaling pathways, derepressing the co-stimulatory signals, and accelerating $\mathrm{T}$ cell re-activation. So far, PD1/PD-L1 monoclonal antibodies (mAbs) have achieved encouraging results in a series of clinical trials $(3,4,6,8-11)$. In particular, atezolizumab (anti-PD-L1 mAb), nivolumab(anti-PD1 mAb), and pembrolizumab (anti-PD1 mAb) have already been approved with durable clinical response and prolonged overall survival (OS), reaching clinics for the treatment of melanoma, non-small cell lung cancer (NSCLC), and renal cell carcinoma (RCC) $(6,12)$. Despite these advancements, the usage of ICIs still faces great challenges, including unexpected adverse effects, slow-onset time as well as the limited responsive ratio $(4,7$, 13). Therefore, there is an urgent need to uncover reasons for underlying unresponsiveness and accurately target the putative benefiters of PD1/PD-L1 blockade among overall patients. Fortunately, a growing number of studies have evidenced that the gut microbiome could contribute significantly to enhancing anti-PD1/PD-L1 therapeutic responses (14-16).

The gut microbiome refers to the diverse species of nearly $10^{14}$ microorganisms that inhabit along the intestinal lumen, including bacteria, fungi, viruses, protozoa, and archaea $(17,18)$. Over recent years, accumulating evidence has highlighted that the gut microbes have actively involved in the initiation, progression, as well as treatment of a variety of diseases such as diabetes, inflammatory bowel disease (IBD), and even cancers (19). Furthermore, it was also emphasized that the gut flora probably function in the modulation of PD1/PD-L1 blockade through bacteria translocation or sending bacteria-derived molecules to enhance antigenicity and endeavor anti-tumor immune response, which was proved by evidence that certain microbiota types were explicitly found to be enriched in ICI effective patients while some corresponded with the nonresponsiveness of PD1/PD-L1 blockade (20-24). In this case, we would discuss the role of the gut microbiome in anti-PD1/ PD-L1 therapy and its putative mechanisms, manipulation strategies as well as the prospect of clinical application in this review.

\section{HARNESS THE POWER OF HOST IMMUNE SYSTEM TO COMBAT CANCER: PD1/PD-L1 BLOCKADE IN IMMUNOTHERAPY}

As a multifactorial disease, cancer is the result of genetic susceptibility and oncogenic stimulants (25). In spite of progressive understanding of cancer etiology and bioactivities, surgery, chemotherapy, and radiotherapy still comprise the standard treatments in a majority of invading tumors (26). Nevertheless, unprecise target selectivity and treatmentinduced toxicities remain the two most critical issues of these traditional therapeutic methods (25). Notably, in the past few decades, the idea to harness the power of the immune system and revive the compromised anti-cancer immunosurveillance has come into sight, pushing forward the development of cancer immunotherapy. A variety of approaches were included in the field of immunotherapies, ranging from active stimulation (reactivate the immune effectors) to passive ones (counteract the inhibitory cellular mechanisms), with PD1/PD-L1 inhibitors becoming one of the most applied therapy in treating various solid and hematologic tumors $(3,4)$.

PD1/PD-L1 inhibitors are monoclonal antibodies that specifically block membrane receptors that are involved in the immunosuppressive signaling pathway, thus unleashing the immune tolerance of tumor-infiltrating lymphocytes (TILs) within the tumor microenvironment (TME) and invigorating endogenous antitumor response to tumor lesions (27). PD1 is a co-inhibitory receptor predominantly expressed on several immune cells, including activated $\mathrm{T}$ cells, B cells, natural killer (NK) cells, and dendritic cells (DCs) $(28,29)$. During $\mathrm{T}$ cell activation, the PD1 expression is provoked by the cytokines (IL$2,7,15,21)$ after the antigen-specific engagement of $\mathrm{T}$ cell receptors (TCR) with major histocompatibility complex (MHC), essentially prohibiting the hyperactivation of self-reactive T cells. In general, there are two corresponding ligands for PD1, named PD-L1 and PD-L2; both are continuously expressed by antigen-presenting cells (APCs) to sustain immune tolerance and refrain from excessive autoimmunity and improper peripheral damage $(30,31)$. The exact role of PD-L2 in cancer immunity is yet unstated. However, the peripheral binding of PD1/PD-L1 is responsible for the resistance of cytotoxic T-lymphocytes (CTLs) mediated cytolysis as well as Fas-induced cellular apoptosis (32-36). Within the TME, the release of IFN- $\gamma$ and stimulation of oncogenic drivers could provoke PD-L1 overexpression on tumor cells through inhibiting PI3K-AKT and Ras-Raf-MEK-ERK mediated pathways (37). Therefore, the subsequent binding of PD1 to PD-L1 serves as a brake for $\mathrm{T}$ cell activation in the tumor bed, driving $\mathrm{T}$ cell exhaustion, apoptosis, and neutralization processes, thus leading to tumor cell survival and unlimited proliferation (38). Notably, PD1/PD-L1 blockers has also achieved significant clinical efficacy against treating various solid and hematologic malignancies. Correspondingly, there are several clinically available PD1/PD-L1 inhibitors approved by FDA for cancer treatment ranging from melanoma to NSCLC, including but not restricted to pembrolizumab, nivolumab, atezolizumab, and avelumab. More importantly, during early phase II trials, the single agent alone yielded encouraging clinical results (39). The atezolizumab alone met its expected endpoint with prominent survival benefits and adequate safety profiles compared to applying chemotherapeutic docetaxel (40). In addition, the anti-PD1 nivolumab, which was designated as the frontline pharmaceutics for melanoma treatment, showed favorable clinical responses with durable sustaining effects and low relapse rate compared to conventional chemotherapies 
(41). Combinatorial therapy of anti-CTLA-4 and anti-PD-L1 blockade displayed more evident tumor regression in approximately $50 \%$ of patients with advanced melanoma, in some cases, more than $80 \%$ of total patients were presented with disease remission and long-term free survival $(42,43)$.

Though PD1/PD-L1 blockade has displayed significant clinical results, it also accompanies a spectrum of toxic events (44). Especially with anti-PD1/PD-L1 therapy, immune-related adverse events (irAEs) are the most frequently occurring types (44-46). IrAEs in PD1/PD-L1 inhibition commonly present with general systemic toxicity such as fatigue, headache, fever, nausea, diarrhea, rash, pruritus, etc. (47). It could also manifest with specific organ destruction, with the skin, thyroid gland, pituitary gland, liver, lung, and GI tract being the most susceptible sites $(44,45)$. In short, these all underline the necessity of multidisciplinary collaboration and consensus monitoring of irAEs. Interestingly, in recent years, mounting evidence has proposed that microbiota could mitigate the PD1/PD-L1 related toxicities to some extent, further indicating its potential role in modulating the effectiveness and prognosis of anti-PD1/ PD-L1 therapy.

\section{THE INTERPLAY BETWEEN GUT MICROBIOME AND HOST IMMUNITY}

The symbionts residing in the gastrointestinal tract contribute significantly to sustaining the homeostasis and overall health of the host. As a pivotal regulator of the digestive system, gut commensals actively participate in the digestion of nutrients, fermentation of dietary fibers, synthesis of necessary vitamins as well as competition for pathogenic invasion, thus maintaining the stability of the gut microenvironment (48). Consequently, disruption of the balance of microbial configuration may result in the break out of numerous diseases, even cancer $(27,48)$. In particular, specific bacteria species are proved to involve in the oncogenic process to favor tumor immortality. For instance, enterotoxigenic Bacteroides fragilis facilitates colorectal cancer progression by generating metalloproteinase, an enzyme that specifically ruins the integrity of the gut mucosal barrier, which in turn increases the exposure risks for pathogens and establishes an immunodeficient gut microenvironment (48). Apart from driving oncogenicity, the intestinal flora is also estimated to influence host immunity multifacetedly. Recently, it has been recognized that gut dysbiosis is intimately associated with the initiation of various immunological disorders such as IBD, celiac disease, rheumatoid arthritis, type- 1 diabetes as well as asthma (19). Notably, the gut microbiota is believed to hold complicated crosstalk with the host immune system both locally and systemically, which also hints at its therapeutic effect in manipulating the immunological responses of PD1/PD-L1 blockade $(18,49-53)$.

The gut microbiota primarily regulates the local host immunity by establishing the competent mucosal immune system, which is referred to as the "second" immune system with unique structures and independent features (54). The physical epithelial barrier is covered with a thick layer of mucus, which is comprised of mucus proteins produced by goblet cells, mucins enriched with antimicrobial peptides as well as immunoglobulin A secreted by B cells (49). The defense of the mucus layer could protect the internal intestinal wall from bacterial adhesion, invasion, and colonization (54). In addition, the gut-associated lymphoid tissues residing in the lamina propria are also crucial counterparts in the mucosal immune system, consisting of groups of histological lymphoid tissues (Peyer's patches, lymphoid follicles, and mesenteric lymph nodes) and dispersing lymphocytes (DCs, T cells, and B cells, etc.) (54). Generally, the gut microbiota executes its modulatory role in the local gut immunity through the following three manners: (1) regulate the regional $\mathrm{B}$ cell function via promoting IgA secretion (55), (2) moderate the differentiation of Th17 cells and Treg cells to organize the balance between inflammatory response and immune tolerance (56), (3) modify the function of $\gamma \delta$ intraepithelial cell for invasive signal detection (57). In short, the gut microbiome could mobilize the mucosal effector cells and promote the secretion of associated immunomodulatory factors, thus actively participating in the regeneration and maintenance of the mucosal immune system.

Nonetheless, the effect of microbiota is not only limited to completing the localized immunity of the gut but also comes into play at distant sites to influence the overall immune tone $(18,49)$. Systemically, the gut microbiota has been validated to produce and release microbiota-derived molecular substances into blood circulation to influence the immune responses of distant tissues and organs, managing the development and mobilization of systemic immune cells (DC priming, lymphocyte homing, recirculation, and cross-reactivation) and recognizing signals from Toll-like receptors, thus altering the immune response of extraintestinal diseases $(18,49,54)$. In brief, the colonization of gut bacteria is indispensable during the maturation of the host immune system, playing an essential part in maintaining intestinal mucosal homeostasis via protecting the integrity of the intestinal barrier and shaping a competent immune system through the systemic mobilization of immune effectors.

\section{GUT MICROBIOTA MODULATES THE EFFICACY OF ANTI-PD1/PD-L1 IMMUNOTHERAPY}

Unlike other cancer therapies, PD1/PD-L1 inhibitory immunotherapy mainly functions via specifically occluding the immunoinhibitory PD1 or PD-L1 sites, thus boosting the endogenous host immunity. Considering the previous work of the synergistic effects of Bacteroides fragilis on CTLA-4 blockers, it is also estimated that the therapeutic outcome of anti-PD1/PD-L1 therapy could also be drastically influenced by microbiota, which has been verified in both preclinical and clinical studies (Table 1).

The immunomodulatory role of gut microbiota in PD1/PDL1 inhibiting therapy was firstly investigated in preclinical murine models. Back in 2015, Sivan et al. explored the 
TABLE 1 | Regulatory role of gut microbiota in anti-PD1/PD-L1 therapy.

\begin{tabular}{|c|c|c|c|c|c|c|}
\hline Bacteria & $\begin{array}{l}\text { Applied anti- } \\
\text { PD1/PD-L1 } \\
\text { immunotherapy }\end{array}$ & $\begin{array}{l}\text { Preclinical and } \\
\text { clinical cohort }\end{array}$ & $\begin{array}{l}\text { Modulatory effects on } \\
\text { anti-PD1/PD-L1 therapeutic } \\
\text { responses }\end{array}$ & & $\begin{array}{l}\text { Possible Mechanisms of } \\
\text { Associated Microbiota }\end{array}$ & References \\
\hline Bifidobacterium spp. & $\begin{array}{l}\text { Anti-PD-L1 } \\
\text { blockade }\end{array}$ & $\begin{array}{l}\text { Mice model } \\
\text { bearing melanoma }\end{array}$ & $\begin{array}{l}\text { a). Anti-tumor effects, preventing } \\
\text { tumor growth and expansion } \\
\text { b). Synergistic role with anti-PD-L1 } \\
\text { therapy }\end{array}$ & $\begin{array}{l}\text { a). } \\
\text { b). }\end{array}$ & $\begin{array}{l}\text { Inducing DCs maturation and } \\
\text { activation } \\
\text { Increasing accumulation of } \mathrm{CD}^{+} \\
\mathrm{T} \text { cells in tumor beds }\end{array}$ & Sivan et al. (20) \\
\hline Akkermansia muciniphila & $\begin{array}{l}\text { Anti-PD1 } \\
\text { blockade }\end{array}$ & $\begin{array}{l}\text { a). GF or ATB } \\
\text { treated mice } \\
\text { b). Patients with } \\
\text { advanced } \\
\text { NSCLC, } \\
\text { RCC, or UC }\end{array}$ & $\begin{array}{l}\text { a). Potent clinical response in } \\
\text { responders receiving anti-PD1 } \\
\text { therapy but not in non- } \\
\text { responders } \\
\text { b). Facilitating anti-PD1 therapy }\end{array}$ & $\begin{array}{l}\text { a). } \\
\text { b). }\end{array}$ & $\begin{array}{l}\text { Motivating DCs, promoting IL-12 } \\
\text { production } \\
\text { Recruitment of } \mathrm{CD}^{+} \mathrm{CCR}^{+} \mathrm{T} \\
\text { cells and } \mathrm{CD} 4^{+} \mathrm{CXCR}^{+} \mathrm{T} \text { cells } \\
\text { into TME, reducing Tregs ratio }\end{array}$ & Routy et al. (22) \\
\hline $\begin{array}{l}\text { Bifidobacterium longum, } \\
\text { Enterococcus faecium, and } \\
\text { Collinsella aerofaciens }\end{array}$ & $\begin{array}{l}\text { Anti-PD1 } \\
\text { blockade }\end{array}$ & $\begin{array}{l}\text { Metastatic } \\
\text { melanoma patients }\end{array}$ & $\begin{array}{l}\text { a). Improving the tumor control in } \\
\text { responders } \\
\text { b). Enhanced efficacy of anti-PD1 } \\
\text { blockade }\end{array}$ & $\begin{array}{l}\text { a). } \\
\text { b). }\end{array}$ & $\begin{array}{l}\text { Enhanced DCs function and } \\
\text { greater Th1 cell responses } \\
\text { Decreased Tregs in the } \\
\text { periphery }\end{array}$ & $\begin{array}{l}\text { Matson et al. } \\
(58)\end{array}$ \\
\hline $\begin{array}{l}\text { Ruminococcaceae/ } \\
\text { Faecalibacterium/ } \\
\text { Clostridiales }\end{array}$ & $\begin{array}{l}\text { Anti-PD1 } \\
\text { blockade }\end{array}$ & $\begin{array}{l}\text { Advanced } \\
\text { melanoma patients }\end{array}$ & $\begin{array}{l}\text { a). Responders present with } \\
\text { boosted anti-tumor immunity } \\
\text { b). Enhanced anti-PD1 therapeutic } \\
\text { responses in responders }\end{array}$ & $\begin{array}{l}\text { a). } \\
\text { b). }\end{array}$ & $\begin{array}{l}\text { Elevating the level of effector } \\
\text { CD4 }{ }^{+} \text {and } C D 8^{+} T \text { cells in } \\
\text { peripheral blood and tumor bed } \\
\text { Decreasing the number of Tregs } \\
\text { and MDSCs }\end{array}$ & $\begin{array}{l}\text { Gopalakrishnan } \\
\text { et al. (21) }\end{array}$ \\
\hline $\begin{array}{l}\text { Alistipes putredinis, } \\
\text { Bifidobacterium longum, and } \\
\text { Prevotella copri }\end{array}$ & $\begin{array}{l}\text { Anti-PD1 } \\
\text { blockade }\end{array}$ & $\begin{array}{l}\text { Chinese NSCLC } \\
\text { patients }\end{array}$ & $\begin{array}{l}\text { a). Higher microbiome diversity } \\
\text { correspond with prolonged PFS } \\
\text { in patients } \\
\text { b). Synergistic function in anti-PD1 } \\
\text { therapy }\end{array}$ & $\begin{array}{l}\text { a). } \\
\text { b). }\end{array}$ & $\begin{array}{l}\text { Increasing the aggregation of } \\
\text { tumor infiltrating } \mathrm{CD}^{+} \mathrm{T} \text { cells in } \\
\text { the TME } \\
\text { Promoting memory } \mathrm{T} \text { cell and } \\
\text { NK cell function }\end{array}$ & Jin et al. (23) \\
\hline
\end{tabular}

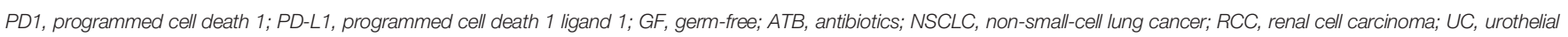

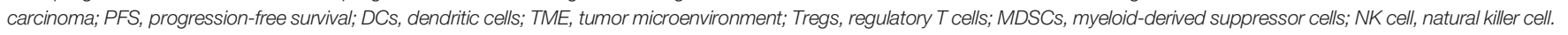

stimulatory role of Bifidobacterium (including Bifidobacterium breve, Bifidobacterium longum, and Bifidobacterium adolescentis) in assisting the anti-tumor response elicited by anti-PD-L1 mAbs (20). The abundance of Bifidobacterium was proved to sufficiently reinforce the cytotoxic $\mathrm{T}$ cell response and impede the tumor growth in melanoma-bearing mice primarily via enhancing DCs function (20). As Sivan et al. stated, the enrichment of Bifidobacterium in responders was validated to upregulate the gene expression in DCs, increase cytokine production, drive DCs maturation and enhance $\mathrm{CD}^{+} \mathrm{T}$ cells priming and accumulation in the TME. Meanwhile, the threshold for DC activation declines while IFN- $\gamma$ production and TILs proliferation increase, allowing for mobilized antigenpresenting ability, upregulated circulating lymphocytes recruitment, and robust effector cell priming, together resulting in immune potentiation and tumor regression (Figure 1A) $(20,59)$.

Furthermore, four other clinical analogous studies of the human microbiome in advanced tumor patients to identify the immunoregulatory role of specific bacteria genres in PD1/PD-L1 blockade were carried out in the following years. In the study of Routy et al., the antibiotic intervention was explored and believed to largely perturb the anti-PD-L1 therapeutic efficacy caused by gut dysbiosis, contributing to the subsequential relapse and shortened survival rate in NSCLC and RCC patients (22). However, the specific enrichment of Akkermansia muciniphila extracted in responders could essentially reverse this disadvantageous circumstance, bringing in overt effector $\mathrm{T}$ cell action. A. muciniphila is estimated to promote tumor-killing activity in an IL-12 dependent manner mediated via DCs motivation. Moreover, exposure to A. muciniphila is correlated with enhanced trafficking of CC-chemokine receptor 9 (CCR9)expressing $\mathrm{T}$ helper cells into mesenteric lymph nodes, following the accumulation of $\mathrm{CD}^{+}{ }^{+} \mathrm{CXCR} 3^{+} \mathrm{T}$ cells into tumor-draining lymph nodes, finally leading to enhanced cytotoxic $\mathrm{T}$ cell response as well as reduced regulatory $\mathrm{T}$ cell ratio in the TME (Figure 1B) $(20,60)$. In consistent with the above study, concerning the melanoma patient cohort, Matson et al. revealed that the enrichment of Bifidobacterium longum, Enterococcus faecium, and Collinsella aerofaciens was positively correlated with augmented systemic $\mathrm{T}$ cell response, optimized tumor control, and improved immune-potentiating effect of anti-PD1 (Figure 1A) (58). On the contrary, Gopalakrishnan et al. reported significant divergence in the multiplicity and composition of the gut microbes in responders, with Clostridiales/Ruminococcaceae/Faecalibacterium being the most colonized strains. The collection of Faecalibacterium spp. enriched in the responders of anti-PD1 treatment was in positive correlation with extended progression-free survival (PFS), in parallel with increased frequency of circulating $\mathrm{CD}^{+}$ and $\mathrm{CD}^{+} \mathrm{T}$ cells and stabilized cytokine action in peripheral blood; whereas Bacteroides enriched in the non-responders failed to do so, increasing the recurrence risks instead (Figure 1C) (21). Conversely, the immunosuppressive circulatory cells such as regulatory $\mathrm{T}$ cells (Tregs) and myeloid-derived suppressor cells (MDSCs) were observed to be relatively reduced to some extent 


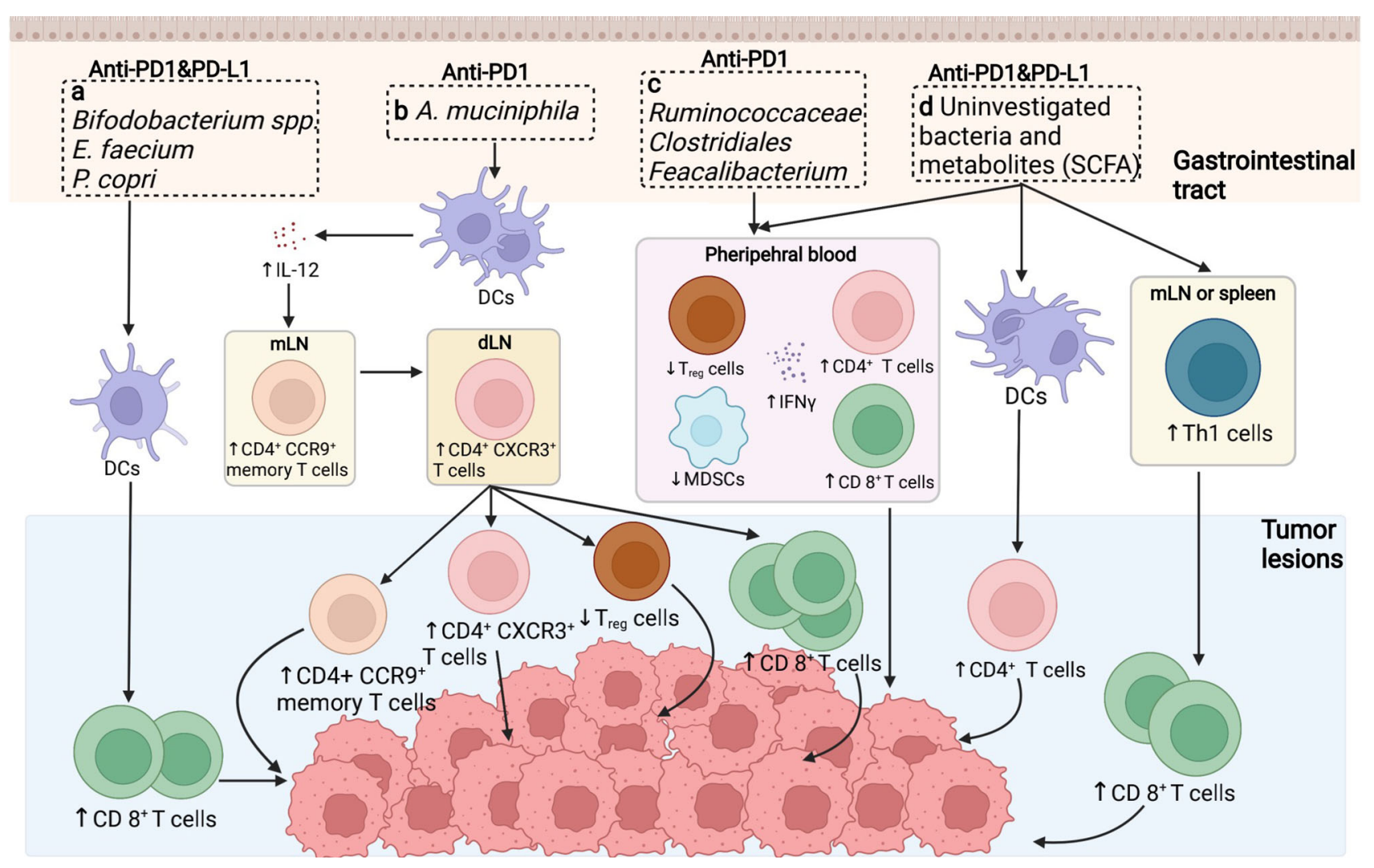

FIGURE 1 | Putative mechanisms concerning the role of the gut microbiome in anti-PD1/PD-L1 immunotherapy. (A) In preclinical murine models, the abundance of Bifidobacterium spp./Enterococcus faecium etc. was shown to increase the cytotoxic T cell function in cancerous sites to facilitate tumor killing. (B) The enrichment of Akkermansiacea muciniphila in anti-PD-L1 responders is correlated with enhanced dendritic cells (DCs) activation, thus provoking IL-12 secretion, promoting the trafficking of $\mathrm{CD}^{+} \mathrm{CCR}^{+}$memory T cell and $\mathrm{CD}_{4}^{+} \mathrm{CXCR} 3^{+} \mathrm{T}$ cells from mesentery lymph nodes ( $\mathrm{mLNs}$ ) to tumor draining lymph nodes (dLNs), ultimately enhancing anti-tumor effect by motivating effector T cells. (C) Ruminococcaceae/Clostridales/Feacalibacterium in the Gl tract mediate in anti-tumor effect via enhancing the ratio of $\mathrm{CD}^{+}{ }^{+}$and $\mathrm{CD}^{+}{ }^{+} \mathrm{T}$ cell ratio while downregulating the activity of regulatory T cells and myeloid derived suppressor cells (MDSCs). (D) Bacteria themselves and associated metabolites are also potential regulators in anti-PD1/PD-L1 therapy, primarily via driving Th1 cell differentiation peripherally, potentiating DCs function as well as diminishing circulating regulatory T cells ( $T_{\text {regs }}$, thus ameliorating immunosuppression and reinforcing immune activation.

(Figure 1C) (21, 59). Besides, in terms of the cohort of Chinese NSCLC patients, Jin et al. investigated the interrelationship between the gut microbiota configuration and anti-PD1 blockade efficacy, illustrating another distinct bacterial makeup in well responders, consisting of Alistipes putredinis, Bifidobacterium longum, and Prevotella copri (Figure 1A) (23).

Presumably, specific bacteria translocation and bacteriaderived metabolites are considered as other putative mechanisms to facilitate anti-PD1/PD-L1 therapy $(20,24,61)$. Despite that direct bacteria translocation was not evidently marked during PD1/PD-L1 targeting therapy, it might also facilitate anti-PD1/PD-L1 response due to the amelioration of peripheral immune tolerance (62). Gaining access to the mesenteric lymph nodes, spleen, and tumor lesions crossing the impaired gut barrier, translocated bacteria promote the differentiation of Th1 cells in secondary immune organs in the periphery, later unleashing immunosuppression and activating lymphocytes recirculation to facilitate PD1 blockade in tumor beds (Figure 1D) $(63,64)$. Besides, microbial metabolites could also act as immunomodulators, with short-chain fatty acid (SCFA) being one of the most investigative bioactive byproducts (61). Primarily, SCFA could be utilized by intestinal epithelial cells as a source of energy; in turn, these metabolites also exert a broad range of effects on host immunity, mainly mediating in the processes of cytokine production, antigen-presenting activities, and Treg differentiation, eventually affecting the anti-PD1/PD-L1 efficacy (Figure 1D) (65). Moreover, Geller et al. reported that viable bacteria were found to colonize in human pancreatic ductal adenocarcinoma, suggesting that tumor microbiota might exert molecular mimicry on tumor cells and influence the PD1/PD-L1 blockade outcomes as well (not confirmed yet) (66). Nevertheless, evidence regarding this theory is inconsistent among studies, which requires validating experiments to further confirm its contribution towards augmented immunostimulatory effects (67).

Excitingly, apart from directly affecting ICI outcome, divergence in the microbial composition may also provide 
clinical value for assessing the ICI-derived toxicity scores. Evidence from both preclinical and clinical studies has characterized the contribution of gut microbes on regulating the occurrence of ICI-derived adverse effects. Considering that anti-CTLA-4-treated melanoma patients rich in Bacteroidetes harness a lower risk for colitis mediated by the Tregs differentiation process, efforts to explore whether the anti-PD1/ PD-L1 related toxicity could also be ameliorated in a bacteriadependent manner are currently on the way (68). Based on the available literature, bacteria belonging to the Ruminococaceae family were identified to optimize both response and irAEs towards ICI therapy (69). In addition, although Bacteriodales represented a typical sign of non-responders, increased colonization of this genre was found to correlated with a lower frequency of ICI-induced autoimmune disease $(69,70)$.

\section{CHALLENGES, CLINICAL APPLICATION, AND POSSIBLE STRATEGIES OF GUT MICROBIOTA APPLIED IN PD1/PD-L1 BLOCKADE}

\section{Applying Fecal Microbiota Transplantation in Anti-PD1/PD-L1 Therapy}

Aiming to achieve an enhanced therapeutic efficacy and abrogate the treatment-associated adverse events of PD1/PD-L1 blockade, several pilot interventional strategies are currently underway to probe into the feasibility in manipulating gut microbes in cancer patients based on prior microbiota modulatory experience applied in other disorders. Among all, fecal microbiota transplantation (FMT) is now one of the most well-established pathways in modifying gut microbiota composition (71).

FMT is defined as transferring the gut microbiome from the donor entirely contained in stool suspension to the recipient, aiming to recover the microbial ecosystem in non-responsive patients (72). Nevertheless, FMT was not commonly applied until it was first reported to successfully treat Clostridium difficile infection (CDI) in 1982 (73). Nowadays, FMT has been approved into standard guidelines for recurrent CDI treatment, with its effectiveness approaching over 90\% (74). Moreover, it has been pointed out that FMT could also boost therapeutic efficacy in other intestinal-dysbiotic-derived diseases such as IBD, which has aroused interest in the potential of applying FMT in cancer management, especially for overcoming ICI-resistant cancers as well as ameliorating ICI-associated toxicities $(72,75,76)$. For instance, FMT was proved to re-establish the microbial diversity both preclinically and clinically, presumably via preventing hepatic necrosis progression and ameliorating cognitive function to improve hepatic encephalopathy status (77). Besides, FMT from healthy individuals could also significantly relieve radiotherapy-induced enteritis in irradiated mice by reorganizing the microbial ecosystem, thus improving the overall survival status (78). More importantly, concerning the previous supportive role of FMT in the ICI-nonresponsive cohort (79), FMT may represent a promising approach to facilitate ICI therapy. Baruch et al. investigated the safety and efficacy of introducing FMT in ten melanoma patients who suffered from PD1-refractory metastases when re-applying anti-PD1 therapy. Three out of ten displayed clinical responses, with two presented with a complete response and one partial response, potentially mediated through gene expression profile shifting and immune cell mobilization in both intestinal mucosa and TME (80). Meanwhile, Davar et al. claimed that patients carrying PD1-resistant melanoma could benefit from a combinatory approach of FMT and anti-PD1 therapy primarily through modulating microbiota composition and reprogramming the immune tone (81). Furthermore, FMT is also believed to abrogate immunotherapy-related toxicities. For example, supplementation of a cocktail of "beneficial bacteria" including Bacteroidales and Burkholderiales via FMT has been reported to relieve the ICI-induced colitis in antibiotic-exposed mice (82). Taken all, more ongoing clinical trials incorporating modulation of microbiota via FMT in cancer therapies are now in their infant stage, though several clinical tests have exhibited much excitement (NCT04130763, NCT04056026, NCT03341143, etc.) (83).

Despite all these hopes, the usage of FMT is still confined with several limitations. Firstly, transferring fecal content from donor to recipient may pose great risks for infection, even causing death (75). Although FMT is proposed to lessen ICI-induced toxicities with fewer side effects, the minimal sample size and insufficient mechanistic explanation appeal for further validation (84). Moreover, FMT is clouded by uncertainties concerning the undefined boundary of beneficial bacteria (24). When performing FMT, disease-promoting bacteria and antimicrobial pathogens could also be accidentally transmitted to the recipient, leading to unanticipated secondary effects such as obesity and carcinogenesis $(24,85)$. As such, extensive microbial screening regardless of bacteria, viruses, and parasites before conducting FMT would help to reduce the risks. Moreover, optimal donor choosing and proper sequencing, cultivating, and encapsulating skills for biologically activated commensals are also noteworthy taking into account. Also, a series of inclusion criteria should be considered, including but not limited to safety, standardized delivery methods, optimal FMT regimens, desired FMT duration, and basal host immunity variations (71). Hence, further microbial profiling of the donors and recipients as well as clearly illustrated mechanistic insights are crucial to achieving the maximal clinical value of FMT $(85,86)$.

\section{Administration of Probiotics as a Potential Tool in PD1/PD-L1 Blockade}

There are also growing numbers of trials investigating the feasibility of oral administration of live bacteria consortia or putative beneficial commensals encapsulated inside the pills in the form of probiotics (87). In general, probiotics refer to groups of bacteria that benefit human health when ingested in sufficient amounts, with the advantage of simplicity, portability, and applicability. First hypothesized by Élie Metchnikoff in the early 1900s, probiotics were aimed to replace the harmful bacteria with beneficial ones, thus modulating gut microbial 
constitution and reversing immunosuppressive tone $(88,89)$. Basically, probiotics could exert beneficial effects via the following mechanisms: (1) confer colonization resistance against pathogenic bacterial strains via competing for nutrients and adhesion with pathogens, (2) stabilize the overall mucosal immunomodulation, (3) protect the integrity of the mucosal barrier via producing antimicrobial factors such as defensins and bacteriocins, (4) target and degrade gut toxins in the colon $(90,91)$.

Nevertheless, probiotics have been proposed to prevent and treat several diseases, their application in therapy still lacks consensus clarity. Early pre-clinical studies revealed the supportive role of administering probiotic mixture VSL\#3 in mice undergoing chemotherapy, which showed substantial effectiveness in ameliorating irinotecan-induced diarrhea and weight loss (92). Furthermore, A. muciniphila administration was proved to boost the therapeutic effects in antibiotic-exposed mice receiving anti-PD1 therapy, and Bifidobacterium supplement largely reversed the anti-PD-L1 resistant status in melanoma-bearing mice, indicating its potential role in assisting PD1/PD-L1 blockade efficacy $(20,22)$. Recently, Tanoue et al. isolated 11 commensal strains that were capable of motivating IFN- $\gamma$ producing $\mathrm{T}$ cells from the gut of germ-free mice, which were rarely found in human intestines. Feeding and recolonizing these strains significantly boosted anti-PD1 and anti-CTLA-4 therapeutic responses in tumor-bearing mice, indicating their synergistic role in assisting ICI therapy (93). Moreover, several pioneer trials applying probiotics for treating malignancies have been planned and implemented in action. For example, in trial NCT03817125, the orally delivered probiotics (SER-401) are supplied along with PD1 blockade therapy to metastatic melanoma patients, focusing on the clinical efficacy, potential toxicity, overall safety, host immune response alterations, as well as microbiota compositional change (71). A processing trial incorporates a diverse range of cancer patients, including melanoma, NSCLC, RCC, and bladder cancer candidates, employing defined bacteria strains (MRx0518) together with regular anti-PD1 ICI therapy, expecting to observe clinical efficacy (71). Another phase I trial aims to evaluate the effect of the probiotic Clostridium butyricum CBM588 strain in combination with nivolumab and ipilimumab in treating patients with kidney cancer (NCT03829111) (94).

Nonetheless, those probiotics that are deemed to be applied as dietary supplements are not strictly granted by the FDA review process before going into the market. In other words, lessregulated consumables lack definite scientific evidence, further indicating that their impact on gut flora and overall health may be pretty confined (95). Moreover, conflicting results also exist concerning its role in immunotherapy. In the study of Suez et al., providing an 11-strain probiotic cocktail resulted in delayed reconstitution of indigenous microbial flora instead of synergistic effect. In contrast, the application of FMT successfully reversed the dysbiotic state in the antibiotictreated human cohort (96). What's more, opportunistic probiotic translocation may appear in the circumstance of immunocompromised patients with a deficient and damaged intestinal barrier, which could pose risks for localized and systemic infectious complications, finally leading to bacteremia, endocarditis, pneumonia, and even death (89).

\section{The Potential Role of Diet and Prebiotics in Anti-PD1/PD-L1 Immunotherapy}

As noted above, on the one hand, gut microbiota plays a key role in food digestion and nutrients absorption during dietary intake; on the other hand, profound changes in dietary consumption, in turn, leads to the microbiome compositional differentiation as well as their transcriptomics and metabolomic profile alterations to meet the energy needs $(71,87)$. Evidence has claimed that certain bacteria and associated metabolites displayed distinct responses in reply to particular nutrient intake and immunological stimulations, offering preliminary diet manipulation strategies to regulate commensal microbial diversity and strengthen host immunity $(71,87,89)$. In particular, prebiotics was defined firstly by Gibson and Roberfroid in 1995 as non-viable food components (mainly represented as fibers) that benefit overall health by synergizing the expansion of beneficial bacteria (24). Additionally, other substances, such as poly-unsaturated fatty acids (PUFAs) and polyphenols, have also been proposed to possess prebiotic potential. Although prebiotics could promote the proliferation of specific beneficial bacteria consortiums, their effectiveness is largely dependent on the residual commensals inside the host; therefore, it is suggested to be used in the form of symbiotics (89). In general, prebiotics function in the intestines mainly in four ways, including stimulating the growth and enrichment of specific probiotics to combat pathogens and modulate immune response (97), directly interacting with pathogens to prevent the colonization and adhesion of pathogens (98), being selectively fermented by colonized probiotics to produce bioactive postbiotics (e.g., SCFA) (99), being absorbed into intestinal cells to alter the gene expression profiles and enhance IFN- $\gamma$ and IL-10 production in CD4 ${ }^{+} \mathrm{T}$ cells (100).

Meanwhile, intense dietary changes could result in the outgrowth of therapeutic-favorable bacteria, further modifying outcomes of ICI therapies (87). According to David et al., it was demonstrated that a tendency towards high fat, low fiber-based diet would negatively impact the variety of the bacteria community, with a significant reduction in the number of $F$. prausnitzii that facilitate the metabolism of dietary plant polysaccharides found in the fecal samples of healthy individuals (101). In addition, RamirezFarias et al. claimed that the plant polysaccharide inulin was positively correlated with the selection of beneficial bacteria Faecalibacterium and Bifidobacterium species, the two taxa that were recently indicated to be responsible for enhanced responsiveness to PD1/PD-L1 blockade therapy (102). Apart from that, most research also described a cancer-preventing role of prebiotics primarily via assisting in chemotherapy and reducing associated toxicities. Taper et al. observed a potentiated drug efficacy and improved toxicity tolerance in liver tumor-bearing mice treated with six chemotherapeutics (5-FU, doxorubicin, vincristine, 
CTX, MTX, cytarabine) together with inulin or oligofructose instead of treating with chemotherapy alone (103).

Tentative clinical trials on dietary manipulation towards cancer patients are currently underway. A trial termed "BE GONE” trial (NCT02843425) has already begun to investigate the dietary alterations in cancer cohorts, with the intervention of adding another half cup of beans per day into their daily diet, indeed, measuring the shifts in gut commensals and inferring possible effect on their routine therapies (49). Notably, the divergence in host genetic background may plausibly explain the different outcomes concerning prebiotic administration (beneficial or detrimental), further supporting the necessity of designing specific prebiotic regimens based on the interindividual variability in response to prebiotic administration (89). Although these studies stay at their initial stage, both are expected to provide valuable results on how dietary and lifestyle intervention would impact the gut microbial composition, immunological interaction, disease progression as well as the overall outcome of malignancies (49).

\section{Directly Using Postbiotics as a Potential Regulator in PD1/PD-L1 Blockade}

Not restricted to ingestion of viable bacteria in the form of probiotics, the soluble byproducts and metabolites generated from microorganisms also exert bioactive roles on the host's overall health, known as postbiotics (89). The most representative example would be SCFA, which is routinely produced during carbohydrate fermentation. For certain probiotic strains, it is hypothesized that the culture supernatants themselves are capable of displaying bioactive effects in place of administrating live bacteria, postulating that postbiotics, in some circumstances, may overcome the limitation of microbes and serve as a safer and more cost-effective option compared to probiotic intervention in anti-PD1/PD-L1 therapy $(104,105)$.

Up to now, the putative mechanisms underlying the bioactive role of postbiotics are clearly illustrated. For one thing, postbiotics are expected to alleviate colonic inflammation and preserve the gut barrier integrity. For instance, Lactobacillus rhamnosus GG derived protein, named p40, is believed to block cytokine-driven apoptosis of epithelial cells to restore the gut barrier function, thus mitigating intestinal injury and initiating protective immune responses $(89,105,106)$. For another, selective postbiotics, such as ferrichrome extracted from Lactobacillus casei ATCC334 supernatant, could also exhibit potential tumoricidal effects via activating apoptoticassociated signaling axis in colorectal cancer cells (89). Additionally, postbiotics have been shown to facilitate anticancer therapeutic response as well. Lactobacillus plantarum supernatant was reported to potentiate the cytotoxicity of 5-FU activity on colonic cancer cells in vitro, primarily through inducing apoptosis, shortening survival rate, and prohibiting the stemness features of cancer cells (107). Moreover, supernatants from E. coli Nissle 1917 and L. fermentum BR11 were also illustrated to decrease the occurrence of 5-FU-induced mucositis (108).
Furthermore, it is challenging to isolate and match corresponding molecules that specifically contribute to the therapeutic effects due to their complex diversity and substantial metabolites mixture among bacteria. Although the investigation in the postbiotics has been a rapidly developing but relatively uncharted field, more safety and application profiles need to be claimed in clinical settings as this area is becoming more and more understood and matured (89).

\section{CONCLUSIONS}

Cancer is growing as one of the most significant burdens in modern society. Whereas conventional therapies display multiple defects, PD1/PD-L1 blockade immunotherapy seems like a promising choice with favorable clinical efficacy and relatively mild adverse effects. Excitingly, it is suggested that microbiota could serve as a critical determinant in PD1/PD-L1 therapy and alter the therapeutic response as well as treatmentassociated toxicity, which ultimately alters the overall outcomes of patients. Fortunately, the flexibility and modifiability features of gut microbes provide chances for clinical application as a potential modality facilitating cancer management. However, this field is relatively young, and there still remains a great deal of ambiguities and doubts to be solved. As studies reported the positive correlation between the enrichment of favorable bacteria and optimistic anti-PD1/PD-L1 response, the underlying processes of immunomodulation of these species need to be further clarified. While the intestinal bacterial mapping in the responders evidently differs from the non-responders, whether the microbiota composition could be regarded as a biomarker in predicting the consequence and prognosis of the ICI therapy requires validation in the subsequent prospective studies. Despite the existing discrepancies among studies, standardization should be reached regarding the methodology of fecal sample collection, DNA extraction, sequencing method, as well as isolated individual confounding variables for further investigation. Also, larger cohorts should be incorporated to discover potential markers for response evaluation. In addition, the interplay between microbiota and other immuno-oncology modalities other than PD1/PD-L1 inhibitors such as cancer vaccine, $\mathrm{T}$ cell-targeted therapy, and oncolytic virus therapy needs more investigation, which may help to illustrate whether the presence of beneficial consortium is applicable and overlapping in a broad spectrum of immunotherapy. Besides, hiding intrinsic microbial signals from fungi and viruses should also be explored. Furthermore, possible transmission modalities, including FMT, probiotics, diet, prebiotics, and postbiotics, are discussed herein to investigate the putative manipulation methods of gut microbiota. The choice of the most optimal delivery method with prolonged duration remains to be confirmed with additional tests; at the same time, its safety, effectiveness, and flexibility should also be comprehensively evaluated as well, thus making the most of the gut microbiota in PD1/PD-L1 blockade. 


\section{FUTURE PERSPECTIVES}

So far, preclinical evidence has encouraged applying microbial manipulation as a therapeutic strategy to potentiate immune responses, and this approach is currently being tested in ongoing trials with considerable progress. Of note, the application of personalized microbiome therapy may be a promising clinical orientation to favor anti-PD1/PD-L1 blockade (89). In particular, the main point is to figure out the prerequisite for effective intervention. Since not all subjects respond equally to gut microbiota modulation, it highly depends on the baseline characteristics, including overall immune status, genetic background, gut barrier integrity, and microbial diversity. Consequently, the scheme of microbiota manipulation could be designed to fit the personalized microbial spectrum of particular patients. All in all, the ultimate goal of utilizing the microbiome is to both assist in anti-PD1/PDL1 therapy and to reduce the risks for related toxicities. Thus, it is expected that microbiota intervention may become one of the

\section{REFERENCES}

1. WHO Health Statistics and Information Systems. In Projections of Mortality and Causes of Death, 2016 to 2060. WHO (2018).

2. Mattiuzzi C, Lippi G. Current Cancer Epidemiology. J Epidemiol Glob Health (2019) 9(4):217-22. doi: 10.2991/jegh.k.191008.001

3. Farkona S, Diamandis EP, Blasutig IM. Cancer Immunotherapy: The Beginning of the End of Cancer? BMC Med [Internet] (2016) 14(1):1-18. doi: 10.1186/s12916-016-0623-5

4. Sun JY, Lu XJ. Cancer Immunotherapy: Current Applications and Challenges. Cancer Lett (2020) 480:1-3. doi: 10.1016/j.canlet.2020.03.024

5. Padma VV. An Overview of Targeted Cancer Therapy. Biomed (2015) 5 (4):1-6. doi: 10.7603/s40681-015-0019-4

6. Topalian SL, Weiner GJ, Pardoll DM. Cancer Immunotherapy Comes of Age. J Clin Oncol (2011) 29(36):4828-36. doi: 10.1200/JCO.2011.38.0899

7. Kennedy LB, Salama AKS. A Review of Cancer Immunotherapy Toxicity. CA Cancer J Clin (2020) 70(2):86-104. doi: 10.3322/caac.21596

8. Mellman I, Coukos G, Dranoff G. Cancer Immunotherapy Comes of Age. Nature (2011) 480(7378):480-9. doi: 10.1038/nature10673

9. Drake CG. Basic Overview of Current Immunotherapy Approaches in Urologic Malignancy. Urol Oncol Semin Orig Investig (2006) 24(5):413-8. doi: 10.1016/j.urolonc.2005.08.013

10. Davis ID. An Overview of Cancer Immunotherapy. Immunol Cell Biol (2000) 78(3):179-95. doi: 10.1046/j.1440-1711.2000.00906.x

11. Fridman WH, Zitvogel L, Sautès-Fridman C, Kroemer G. The Immune Contexture in Cancer Prognosis and Treatment. Nat Rev Clin Oncol (2017) 14(12):717-34. doi: 10.1038/nrclinonc.2017.101

12. Sharma P, Allison JP. Immune Checkpoint Targeting in Cancer Therapy: Toward Combination Strategies With Curative Potential. Cell (2015) 161 (2):205-14. doi: 10.1016/j.cell.2015.03.030

13. Hegde PS, Chen DS. Top 10 Challenges in Cancer Immunotherapy. Immunity (2020) 52(1):17-35. doi: 10.1016/j.immuni.2019.12.011

14. Zitvogel L, Daillère R, Roberti MP, Routy B, Kroemer G. Anticancer Effects of the Microbiome and Its Products. Nat Rev Microbiol [Internet] (2017) 15 (8):465-78. doi: 10.1038/nrmicro.2017.44

15. Goubet AG, Daillère R, Routy B, Derosa L, M. Roberti P, Zitvogel L. The Impact of the Intestinal Microbiota in Therapeutic Responses Against Cancer. Comptes Rendus - Biol (2018) 341(5):284-9. doi: 10.1016/ j.crvi.2018.03.004

16. Elkrief A, Derosa L, Zitvogel L, Kroemer G, Routy B. The Intimate Relationship Between Gut Microbiota and Cancer Immunotherapy. Gut Microbes [Internet] (2019) 10(3):424-8. doi: 10.1080/19490976.2018. 1527167 following milestones for personalized and precise therapies for cancer treatment.

\section{AUTHOR CONTRIBUTIONS}

TC and ZL provided the concepts of this review and designed its framework. YZ conducted the research, selected the literature findings and wrote the manuscript. All authors edited the manuscript. All authors contributed to the article and approved the submitted version.

\section{FUNDING}

This work was supported by grants from the National Natural Science Foundation of China (no. 82060638) and 'Double 10 -Thousand Plan' of Jiangxi Province (Innovation and Technology Professionals as the High-End Talent).

17. Pickard JM, Zeng MY, Caruso R, Núñez G. Gut Microbiota: Role in Pathogen Colonization, Immune Responses, and Inflammatory Disease. Immunol Rev (2017) 279(1):70-89. doi: 10.1111/imr.12567

18. Yi M, Jiao D, Qin S, Chu Q, Li A, Wu K. Manipulating Gut Microbiota Composition to Enhance the Therapeutic Effect of Cancer Immunotherapy. Integr Cancer Ther (2019) 18:1534735419876351. doi: 10.1177/1534735419876351

19. Levy M, Kolodziejczyk AA, Thaiss CA, Elinav E. Dysbiosis and the Immune System. Nat Rev Immunol (2017) 17(4):219-32. doi: 10.1038/nri.2017.7

20. Sivan A, Corrales L, Hubert N, Williams JB, Aquino-Michaels K, Earley ZM, et al. Commensal Bifidobacterium Promotes Antitumor Immunity and Facilitates Anti-PD-L1 Efficacy. Science (80-) (2015) 350(6264):1084-9. doi: 10.1126/science.aac4255

21. Gopalakrishnan V, Spencer CN, Nezi L, Reuben A, Andrews MC, Karpinets TV, et al. Gut Microbiome Modulates Response to Anti-PD-1 Immunotherapy in Melanoma Patients. Science (80-) (2018) 359(6371):97103. doi: $10.1126 /$ science.aan4236

22. Routy B, Le Chatelier E, Derosa L, Duong CPM, Alou MT, Daillère R, et al. Gut Microbiome Influences Efficacy of PD-1-Based Immunotherapy Against Epithelial Tumors. Science (80-) (2018) 359(6371):91-7.doi: 10.1126/ science.aan3706

23. Jin Y, Dong H, Xia L, Yang Y, Zhu Y, Shen Y, et al. The Diversity of Gut Microbiome is Associated With Favorable Responses to Anti-Programmed Death 1 Immunotherapy in Chinese Patients With NSCLC. J Thorac Oncol (2019) 14(8):1371-89. doi: 10.1016/j.jtho.2019.04.007

24. Fessler J, Matson V, Gajewski TF. Exploring the Emerging Role of the Microbiome in Cancer Immunotherapy. J ImmunoTher Cancer (2019) 30 (1):1-20. doi: 10.1186/s40425-019-0574-4

25. Pavet V, Portal MM, Moulin JC, Herbrecht R, Gronemeyer H. Towards Novel Paradigms for Cancer Therapy. Oncogene (2011) 30(1):1-20. doi: 10.1038/onc.2010.460

26. Li W, Deng X, Chen T. Exploring the Modulatory Effects of Gut Microbiota in Anti-Cancer Therapy. Front Oncol (2021) 11(April):1-11. doi: 10.3389/ fonc.2021.644454

27. Yi M, Yu S, Qin S, Liu Q, Xu H, Zhao W, et al. Gut Microbiome Modulates Efficacy of Immune Checkpoint Inhibitors. J Hematol Oncol (2018) 11(1):110. doi: 10.1186/s13045-018-0592-6

28. Good-Jacobson KL, Szumilas CG, Chen L, Sharpe AH, Tomayko MM, Shlomchik MJ. PD-1 Regulates Germinal Center B Cell Survival and the Formation and Affinity of Long-Lived Plasma Cells. Nat Immunol (2010) 11 (16):535-42. doi: 10.1038/ni.1877

29. Keir ME, Butte MJ, Freeman GJ, Sharpe AH. PD-1 and Its Ligands in Tolerance and Immunity. Annu Rev Immunol (2008) 26:677-704. doi: 10.1146/annurev.immunol.26.021607.090331 
30. Liang SC, Latchman YE, Buhlmann JE, Tomczak MF, Horwitz BH, Freeman GJ, et al. Regulation of PD-1, PD-L1, and PD-L2 Expression During Normal and Autoimmune Responses. Eur J Immunol (2003) 33(10):2706-16. doi: 10.1002/eji.200324228

31. Ghiotto M, Gauthier L, Serriari N, Pastor S, Truneh A, Nunès JA, et al. PD-L1 and PD-L2 Differ in Their Molecular Mechanisms of Interaction With PD-1. Int Immunol (2010) 22(8):651-60. doi: 10.1093/ intimm/dxq049

32. Hirano F, Kaneko K, Tamura H, Dong H, Wang S, Ichikawa M, et al. Blockade of B7-H1 and PD-1 by Monoclonal Antibodies Potentiates Cancer Therapeutic Immunity. Cancer Res (2005) 65(3):1089-96. doi: 10.1093/ intimm/dxq049

33. McLaughlin J, Han G, Schalper KA, Carvajal-Hausdorf D, Pelekanou V, Rehman J, et al. Quantitative Assessment of the Heterogeneity of PD-L1 Expression in Non-Small-Cell Lung Cancer. JAMA Oncol (2016) 2(1):46-54. doi: 10.1001/jamaoncol.2015.3638

34. Schalper KA, Carvajal-Hausdorf D, McLaughlin J, Velcheti V, Chen L, Sanmamed M, et al. Clinical Significance of PD-L1 Protein Expression on Tumor-Associated Macrophages in Lung Cancer. J Immunother Cancer (2015) 3(Suppl 2):P415. doi: 10.1186/2051-1426-3-S2-P415

35. Vassilakopoulou M, Avgeris M, Velcheti V, Kotoula V, Rampias T, Chatzopoulos K, et al. Evaluation of PD-L1 Expression and Associated Tumor-Infiltrating Lymphocytes in Laryngeal Squamous Cell Carcinoma. Clin Cancer Res (2016) 22(3):704-13. doi: 10.1158/1078-0432.CCR-15-1543

36. Schalper KA, Velcheti V, Carvajal D, Wimberly H, Brown J, Pusztai L, et al. In Situ Tumor PD-L1 mRNA Expression is Associated With Increased Tils and Better Outcome in Breast Carcinomas. Clin Cancer Res (2014) 20(10):2773-82. doi: 10.1158/1078-0432.CCR-13-2702

37. Kythreotou A, Siddique A, Mauri FA, Bower M, Pinato DJ. Pd-L1. J Clin Pathol (2018) 71(3):189-94. doi: 10.1136/jclinpath-2017-204853

38. Butte MJ, Keir ME, Phamduy TB, Sharpe AH, Freeman GJ. Programmed Death-1 Ligand 1 Interacts Specifically With the B7-1 Costimulatory Molecule to Inhibit T Cell Responses. Immunity (2007) 27(1):111-22. doi: 10.1016/j.immuni.2007.05.016

39. Brahmer JR, Drake CG, Wollner I, Powderly JD, Picus J, Sharfman WH, et al. Phase I Study of Single-Agent Anti-Programmed Death-1 (MDX-1106) in Refractory Solid Tumors: Safety, Clinical Activity, Pharmacodynamics, and Immunologic Correlates. J Clin Oncol (2010) 28(19):3167-75. doi: 10.1200/JCO.2009.26.7609

40. Rittmeyer A, Barlesi F, Waterkamp D, Park K, Ciardiello F, von Pawel J, et al. Atezolizumab Versus Docetaxel in Patients With Previously Treated NonSmall-Cell Lung Cancer (OAK): A Phase 3, Open-Label, Multicentre Randomised Controlled Trial. Lancet (2017) 389(10066):255-65. doi: 10.1016/S0140-6736(16)32517-X

41. Topalian SL, Sznol M, McDermott DF, Kluger HM, Carvajal RD, Sharfman WH, et al. Survival, Durable Tumor Remission, and Long-Term Safety in Patients With Advanced Melanoma Receiving Nivolumab. J Clin Oncol (2014) 32(10):1020-30. doi: 10.1200/JCO.2013.53.0105

42. Wolchok JD, Kluger H, Callahan MK, Postow MA, Rizvi NA, Lesokhin AM, et al. Nivolumab Plus Ipilimumab in Advanced Melanoma. N Engl J Med (2013) 369(2):122-33. doi: 10.1056/NEJMoa1302369

43. Larkin J, Chiarion-Sileni V, Gonzalez R, Grob JJ, Cowey CL, Lao CD, et al. Combined Nivolumab and Ipilimumab or Monotherapy in Untreated Melanoma. N Engl J Med (2015) 373(1):23-34. doi: 10.1056/ NEJMoa1504030

44. Postow MA, Sidlow R, Hellmann MD. Immune-Related Adverse Events Associated With Immune Checkpoint Blockade. N Engl J Med (2018) 378 (2):158-68. doi: 10.1056/NEJMra1703481

45. Khoja L, Day D, Wei-Wu Chen T, Siu LL, Hansen AR. Tumour- and ClassSpecific Patterns of Immune-Related Adverse Events of Immune Checkpoint Inhibitors: A Systematic Review. Ann Oncol (2017) 28(10):2377-85. doi: 10.1093/ annonc/mdx286

46. Robert C, Schachter J, Long GV, Arance A, Grob JJ, Mortier L, et al. Pembrolizumab Versus Ipilimumab in Advanced Melanoma. N Engl J Med (2015) 372(26):2521-32. doi: 10.1056/NEJMoa1503093

47. Zhang JY, Yan YY, Li JJ, Adhikari R, Fu LW. PD-1/PD-L1 Based Combinational Cancer Therapy: Icing on the Cake. Front Pharmacol (2020) 11. doi: 10.3389/fphar.2020.00722
48. Bultman SJ. The Microbiome and Its Potential as a Cancer Preventive Intervention. Semin Oncol (2016) 43(1):97-106. doi: 10.1053/ j.seminoncol.2015.09.001

49. Gopalakrishnan V, Helmink BA, Spencer CN, Reuben A, Wargo JA. The Influence of the Gut Microbiome on Cancer, Immunity, and Cancer Immunotherapy. Cancer Cell [Internet] (2018) 33(4):570-80. doi: 10.1016/ j.ccell.2018.03.015

50. Li W, Deng Y, Chu Q, Zhang P. Gut Microbiome and Cancer Immunotherapy. Cancer Lett (2019) 447(January):41-7. doi: 10.1016/ j.canlet.2019.01.015

51. Rezasoltani S, Yadegar A, Asadzadeh Aghdaei H, Reza Zali M. Modulatory Effects of Gut Microbiome in Cancer Immunotherapy: A Novel Paradigm for Blockade of Immune Checkpoint Inhibitors. Cancer Med (2021) 10 (3):1141-54. doi: 10.1002/cam4.3694

52. Honda K, Littman DR. The Microbiota in Adaptive Immune Homeostasis and Disease. Nature (2016) 535(7610):75-84. doi: 10.1038/nature18848

53. Zheng D, Liwinski T, Elinav E. Interaction Between Microbiota and Immunity in Health and Disease. Cell Res (2020) 30(6):492-506. doi: 10.1038/s41422-020-0332-7

54. Shui L, Yang X, Li J, Yi C, Sun Q, Zhu H. Gut Microbiome as a Potential Factor for Modulating Resistance to Cancer Immunotherapy. Front Immunol (2020) 10. doi: 10.3389/fimmu.2019.02989

55. Hapfelmeier S, Lawson MAE, Slack E, Kirundi JK, Stoel M, Heikenwalder M, et al. Reversible Microbial Colonization of Germ-Free Mice Reveals the Dynamics of IgA Immune Responses. Science (80-) (2010) 328(5986):17059. doi: 10.1126/science. 1188454

56. Britton GJ, Contijoch EJ, Mogno I, Vennaro OH, Llewellyn SR, Ng R, et al. Microbiotas From Humans With Inflammatory Bowel Disease Alter the Balance of Gut Th17 and Roryt+ Regulatory T Cells and Exacerbate Colitis in Mice. Immunity (2019) 50(1):212-24.e4. doi: 10.1016/ j.immuni.2018.12.015

57. Ismail AS, Severson KM, Vaishnava S, Behrendt CL, Yu X, Benjamin JL, et al. $\gamma \delta$ Intraepithelial Lymphocytes are Essential Mediators of Host-Microbial Homeostasis at the Intestinal Mucosal Surface. Proc Natl Acad Sci U S A (2011) 108(21):8743-8. doi: 10.1073/pnas.1019574108

58. Matson V, Fessler J, Bao R, Chongsuwat T, Zha Y, Alegre ML, et al. The Commensal Microbiome is Associated With Anti-PD-1 Efficacy in Metastatic Melanoma Patients. Science (80-) (2018) 359(6731):104-8. doi: 10.1126/science.aao3290

59. Routy B, Gopalakrishnan V, Daillère R, Zitvogel L, Wargo JA, Kroemer G. The Gut Microbiota Influences Anticancer Immunosurveillance and General Health. Nat Rev Clin Oncol (2018) 15(6):382-96. doi: 10.1038/ s41571-018-0006-2

60. Mullins IM, Slingluff CL, Lee JK, Garbee CF, Shu J, Anderson SG, et al. CXC Chemokine Receptor 3 Expression by Activated CD8+ T Cells is Associated With Survival in Melanoma Patients With Stage III Disease. Cancer Res (2004) 64(21):7697-701. doi: 10.1158/0008-5472.CAN-04-2059

61. Morrison DJ, Preston T. Formation of Short Chain Fatty Acids by the Gut Microbiota and Their Impact on Human Metabolism. Gut Microbes (2016) 7 (3):189-200. doi: 10.1080/19490976.2015.1134082

62. Peters S, Kerr KM, Stahel R. PD-1 Blockade in Advanced NSCLC: A Focus on Pembrolizumab. Cancer Treat Rev (2018) 62:39-49. doi: 10.1016/ j.ctrv.2017.10.002

63. Daillère R, Vétizou $M$, Waldschmitt $N$, Yamazaki $T$, Isnard $C$, PoirierColame V, et al. Enterococcus Hirae and Barnesiella Intestinihominis Facilitate Cyclophosphamide-Induced Therapeutic Immunomodulatory Effects. Immunity (2016) 45(4):931-43. doi: 10.1016/j.immuni.2016.09.009

64. Viaud S, Saccheri F, Mignot G, Yamazaki T, Daillère R, Hannani D, et al. The Intestinal Microbiota Modulates the Anticancer Immune Effects of Cyclophosphamide. Science (80-) (2013) 342(6161):971-6. doi: 10.1126/ science. 1240537

65. Blacher E, Levy M, Tatirovsky E, Elinav E. Microbiome-Modulated Metabolites at the Interface of Host Immunity. J Immunol (2017) 198 (2):572-80. doi: 10.4049/jimmunol.1601247

66. Geller LT, Barzily-Rokni M, Danino T, Jonas OH, Shental N, Nejman D, et al. Potential Role of Intratumor Bacteria in Mediating Tumor Resistance to the Chemotherapeutic Drug Gemcitabine. Science (80-) (2017) 357 (6356):1156-60. doi: 10.1126/science.aah5043 
67. Cremonesi E, Governa V, Garzon JFG, Mele V, Amicarella F, Muraro MG, et al. Gut Microbiota Modulate T Cell Trafficking Into Human Colorectal Cancer. Gut (2018) 67(11):1984-4. doi: 10.1158/1538-7445.AM2018-1001

68. Dubin K, Callahan MK, Ren B, Khanin R, Viale A, Ling L, et al. Intestinal Microbiome Analyses Identify Melanoma Patients at Risk for CheckpointBlockade-Induced Colitis. Nat Commun (2016) 7:10391. doi: 10.1038/ ncomms 10391

69. Chaput N, Lepage P, Coutzac C, Soularue E, Le Roux K, Monot C, et al. Baseline Gut Microbiota Predicts Clinical Response and Colitis in Metastatic Melanoma Patients Treated With Ipilimumab. Ann Oncol (2017) 28 (6):1368-79. doi: 10.1093/annonc/mdx108

70. Frankel AE, Coughlin LA, Kim J, Froehlich TW, Xie Y, Frenkel EP, et al. Metagenomic Shotgun Sequencing and Unbiased Metabolomic Profiling Identify Specific Human Gut Microbiota and Metabolites Associated With Immune Checkpoint Therapy Efficacy in Melanoma Patients. Neoplasia (United States) (2017) 19(10):848-55. doi: 10.1016/j.neo.2017.08.004

71. Khan MAW, Ologun G, Arora R, McQuade JL, Wargo JA. Gut Microbiome Modulates Response to Cancer Immunotherapy. Dig Dis Sci (2020) 65 (3):885-96. doi: 10.1007/s10620-020-06111-x

72. Chen D, Wu J, Jin D, Wang B, Cao H. Fecal Microbiota Transplantation in Cancer Management: Current Status and Perspectives. Int J Cancer (2019) 145(8):2021-31. doi: 10.1002/ijc.32003

73. Schwan A, Sjolin S, Trottestam U, Aronsson B. Relapsing Clostridium Difficile Enterocolitis Cured by Rectal Infusion of Homologous Faeces. Lancet (1983) 2(8354):845. doi: 10.1016/S0140-6736(83)90753-5

74. Surawicz CM, Brandt LJ, Binion DG, Ananthakrishnan AN, Curry SR, Gilligan PH, et al. Guidelines for Diagnosis, Treatment, and Prevention of Clostridium Difficile Infections. Am J Gastroenterol (2013) 108(4):478-98. doi: 10.1038/ajg.2013.4

75. Baruch EN, Gaglani T, Wargo JA. Fecal Microbiota Transplantation as a Mean of Overcoming Immunotherapy-Resistant Cancers - Hype or Hope? Ther Adv Med Oncol (2021) 13:17588359211045853. doi: 10.1177/ 17588359211045853

76. Rohlke F, Stollman N. Fecal Microbiota Transplantation in Relapsing Clostridium Difficile Infection. Ther Adv Gastroenterol (2012) 5(6):40320. doi: $10.1177 / 1756283 X 12453637$

77. Wang WW, Zhang Y, Huang XB, You N, Zheng L, Li J. Fecal Microbiota Transplantation Prevents Hepatic Encephalopathy in Rats With Carbon Tetrachloride-Induced Acute Hepatic Dysfunction. World J Gastroenterol (2017) 23(38):6983-94. doi: 10.3748/wjg.v23.i38.6983

78. Cui M, Xiao H, Li Y, Zhou L, Zhao S, Luo D, et al. Faecal Microbiota Transplantation Protects Against Radiation-Induced Toxicity. EMBO Mol Med (2017) 9(4):448-61. doi: 10.15252/emmm.201606932

79. Kang YB, Cai Y. Faecal Microbiota Transplantation Enhances Efficacy of Immune Checkpoint Inhibitors Therapy Against Cancer. World J Gastroenterol (2021) 27(32):5362-75. doi: 10.3748/wjg.v27.i32.5362

80. Baruch EN, Youngster I, Ben-Betzalel G, Ortenberg R, Lahat A, Katz L, et al. Fecal Microbiota Transplant Promotes Response in ImmunotherapyRefractory Melanoma Patients. Science (80-) (2021) 371(6529):602-9. doi: 10.1126/science.abb5920

81. Davar D, Dzutsev AK, McCulloch JA, Rodrigues RR, Chauvin JM, Morrison RM, et al. Fecal Microbiota Transplant Overcomes Resistance to Anti-PD-1 Therapy in Melanoma Patients. Science (80-) (2021) 371(6529):595-602. doi: $10.1126 /$ science.abf3363

82. Vétizou M, Pitt JM, Daillère R, Lepage $P$, Waldschmitt N, Flament $C$, et al. Anticancer Immunotherapy by CTLA-4 Blockade Relies on the Gut Microbiota. Science (80-) (2015) 350(6264):1079-84. doi: 10.1126/science.aad1329

83. Wu J, Wang S, Zheng B, Qiu X, Wang H, Chen L. Modulation of Gut Microbiota to Enhance Effect of Checkpoint Inhibitor Immunotherapy. Front Immunol (2021) 12. doi: 10.3389/fimmu.2021.669150

84. Wang Y, Wiesnoski DH, Helmink BA, Gopalakrishnan V, Choi K, DuPont HL, et al. Fecal Microbiota Transplantation for Refractory Immune Checkpoint Inhibitor-Associated Colitis. Nat Med (2018) 24(12):1804-8. doi: 10.1038/s41591-018-0238-9

85. Cheng WY, Wu CY, Yu J. The Role of Gut Microbiota in Cancer Treatment: Friend or Foe? Gut (2020) 69(10):1867-76. doi: 10.1136/gutjnl-2020-321153

86. Giles EM, D'Adamo GL, Forster SC. The Future of Faecal Transplants. Nat Rev Microbiol (2019) 17(12):719. doi: 10.1038/s41579-019-0271-9
87. Helmink BA, Khan MAW, Hermann A, Gopalakrishnan V, Wargo JA. The Microbiome, Cancer, and Cancer Therapy. Nat Med [Internet] (2019) 25 (3):377-88. doi: 10.1038/s41591-019-0377-7

88. Mackowiak PA. Recycling Metchnikoff: Probiotics, the Intestinal Microbiome and the Quest for Long Life. Front Public Heal (2013) 1. doi: 10.3389/fpubh.2013.00052

89. Fong W, Li Q, Yu J. Gut Microbiota Modulation: A Novel Strategy for Prevention and Treatment of Colorectal Cancer. Oncogene (2020) 39 (26):4925-43. doi: 10.1038/s41388-020-1341-1

90. Gogineni V K, Morrow LE. Probiotics: Mechanisms of Action and Clinical Applications. J Probiotics Heal (2013) 1:101. doi: 10.4172/23298901.1000101

91. Panebianco C, Andriulli A, Pazienza V. Pharmacomicrobiomics: Exploiting the Drug-Microbiota Interactions in Anticancer Therapies. Microbiome (2018) 6(1):92. doi: 10.1186/s40168-018-0483-7

92. Bowen JM, Stringer AM, Gibson RJ, Yeoh ASJ, Hannam S, Keefe DMK. VSL3 Probiotic Treatment Reduces Chemotherapy-Induced Diarrhea and Weight Loss. Cancer Biol Ther (2007) 6(9):1449-54. doi: 10.4161/cbt.6.9.4622

93. Tanoue T, Morita S, Plichta DR, Skelly AN, Suda W, Sugiura Y, et al. A Defined Commensal Consortium Elicits CD8 T Cells and Anti-Cancer Immunity. Nature (2019) 565(7741):600-5. doi: 10.1038/s41586-019-0878-z

94. Villéger R, Lopès A, Carrier G, Veziant J, Billard E, Barnich N, et al. Intestinal Microbiota: A Novel Target to Improve Anti-Tumor Treatment? Int J Mol Sci (2019) 20(18):1-25. doi: 10.3390/ijms20184584

95. Kristensen NB, Bryrup T, Allin KH, Nielsen T, Hansen TH, Pedersen O. Alterations in Fecal Microbiota Composition by Probiotic Supplementation in Healthy Adults: A Systematic Review of Randomized Controlled Trials. Genome Med (2016) 8(1):52. doi: 10.1186/s13073-016-0300-5

96. Suez J, Zmora N, Zilberman-Schapira G, Mor U, Dori-Bachash M, Bashiardes S, et al. Post-Antibiotic Gut Mucosal Microbiome Reconstitution Is Impaired by Probiotics and Improved by Autologous FMT. Cell (2018) 174(6):1406-23. doi: 10.1016/j.cell.2018.08.047

97. Lindsay JO, Whelan K, Stagg AJ, Gobin P, Al-Hassi HO, Rayment N, et al. Clinical, Microbiological, and Immunological Effects of Fructo-Oligosaccharide in Patients With Crohn's Disease. Gut (2006) 55(3):348-55. doi: 10.1136/ gut.2005.074971

98. Monteagudo-Mera A, Rastall RA, Gibson GR, Charalampopoulos D, Chatzifragkou A. Adhesion Mechanisms Mediated by Probiotics and Prebiotics and Their Potential Impact on Human Health. Appl Microbiol Biotechnol (2019) 103(16):6463-72. doi: 10.1007/s00253-019-09978-7

99. Wong JMW, De Souza R, Kendall CWC, Emam A, Jenkins DJA. Colonic Health: Fermentation and Short Chain Fatty Acids. : J Clin Gastroenterol (2006) 40(3):235-43. doi: 10.1097/00004836-200603000-00015

100. Ito H, Takemura N, Sonoyama K, Kawagishi H, Topping DL, Conlon MA, et al. Degree of Polymerization of Inulin-Type Fructans Differentially Affects Number of Lactic Acid Bacteria, Intestinal Immune Functions, and Immunoglobulin a Secretion in the Rat Cecum. J Agric Food Chem (2011) 59(10):5771-8. doi: 10.1021/jf200859z

101. David LA, Maurice CF, Carmody RN, Gootenberg DB, Button JE, Wolfe BE, et al. Diet Rapidly and Reproducibly Alters the Human Gut Microbiome. Nature (2014) 505(7484):559-63. doi: 10.1038/nature12820

102. Ramirez-Farias C, Slezak K, Fuller Z, Duncan A, Holtrop G, Louis P. Effect of Inulin on the Human Gut Microbiota: Stimulation of Bifidobacterium Adolescentis and Faecalibacterium Prausnitzii. Br J Nutr (2009) 101 (4):541-50. doi: 10.1017/S0007114508019880

103. Taper HS, Roberfroid MB. Nontoxic Potentiation of Cancer Chemotherapy by Dietary Oligofructose or Inulin. Nutr Cancer (2000) 38(1):1-5. doi: 10.1207/S15327914NC381_1

104. Konstantinov SR, Kuipers EJ, Peppelenbosch MP. Functional Genomic Analyses of the Gut Microbiota for Crc Screening. Nat Rev Gastroenterol Hepatol (2013) 10(12):741-5. doi: 10.1038/nrgastro.2013.178

105. Miller PL, Carson TL. Mechanisms and Microbial Influences on CTLA-4 and PD-1-Based Immunotherapy in the Treatment of Cancer: A Narrative Review. Gut Pathog (2020) 12:43. doi: 10.1186/s13099-020-00381-6

106. Yan F, Polk DB. Characterization of a Probiotic-Derived Soluble Protein Which Reveals a Mechanism of Preventive and Treatment Effects of Probiotics on Intestinal Inflammatory Diseases. Gut Microbes (2012) 3 (1):25-8. doi: 10.4161/gmic.19245 
107. An J, Ha EM. Combination Therapy of Lactobacillus Plantarum Supernatant and 5-Fluouracil Increases Chemosensitivity in Colorectal Cancer Cells. J Microbiol Biotechnol (2016) 26(8):1490-503. doi: 10.4014/jmb.1605.05024

108. Prisciandaro LD, Geier MS, Butler RN, Cummins AG, Howarth GS. Probiotic Factors Partially Improve Parameters of 5-Fluorouracil-Induced Intestinal Mucositis in Rats. Cancer Biol Ther (2011) 11(7):671-7. doi: 10.4161/cbt.11.7.14896

Conflict of Interest: The authors declare that the research was conducted in the absence of any commercial or financial relationships that could be construed as a potential conflict of interest.
Publisher's Note: All claims expressed in this article are solely those of the authors and do not necessarily represent those of their affiliated organizations, or those of the publisher, the editors and the reviewers. Any product that may be evaluated in this article, or claim that may be made by its manufacturer, is not guaranteed or endorsed by the publisher.

Copyright $\odot 2022$ Zhou, Liu and Chen. This is an open-access article distributed under the terms of the Creative Commons Attribution License (CC BY). The use, distribution or reproduction in other forums is permitted, provided the original author(s) and the copyright owner(s) are credited and that the original publication in this journal is cited, in accordance with accepted academic practice. No use, distribution or reproduction is permitted which does not comply with these terms. 